\title{
Transplantation of hNT Neurons Into the Ischemic Cortex: Cell Survival and Effect on Sensorimotor Behavior
}

\author{
T.M. Bliss, ${ }^{1 \star}$ S. Kelly, ${ }^{1}$ A.K. Shah,${ }^{1}$ W.C. Foo,${ }^{1}$ P. Kohli, ${ }^{1}$ C. Stokes, ${ }^{1}$ G.H. Sun,${ }^{1}$ \\ M. Ma,${ }^{1}$ J. Masel, ${ }^{2}$ S.R. Kleppner, ${ }^{3}$ T. Schallert,${ }^{4,5}$ T. Palmer, ${ }^{1}$ and G.K. Steinberg ${ }^{1,6}$ \\ ${ }^{1}$ Department of Neurosurgery, Stanford University, Stanford, California \\ ${ }^{2}$ Department of Biological Sciences, Stanford University, Stanford, California \\ ${ }^{3}$ Layton BioScience, Sunnyvale, California \\ ${ }^{4}$ Department of Psychology and Neurobiology, University of Texas at Austin, Texas \\ ${ }^{5}$ Department of Neurosurgery, University of Michigan, Ann Arbor, Michigan \\ ${ }^{6}$ Department of Neurology, Stanford University, Stanford, California
}

Cell transplantation offers a potential new treatment for stroke. Animal studies using models that produce ischemic damage in both the striatum and the frontal cortex have shown beneficial effects when hNT cells (postmitotic immature neurons) were transplanted into the ischemic striatum. In this study, we investigated the effect of hNT cells in a model of stroke in which the striatum remains intact and damage is restricted to the cortex. hNT cells were transplanted into the ischemic cortex 1 week after stroke induced by distal middle cerebral artery occlusion (dMCAo). The cells exhibited robust survival at 4 weeks posttransplant even at the lesion border. hNT cells did not migrate, but they did extend long neurites into the surrounding parenchyma mainly through the white matter. Neurite extension was predominantly toward the lesion in ischemic animals but was bidirectional in uninjured animals. Extension of neurites through the cortex toward the lesion was also seen when there was some surviving cortical tissue between the graft and the infarct. Prolonged deficits were obtained in four tests of sensory-motor function. hNT-transplanted animals showed a significant improvement in functional recovery on one motor test, but there was no effect on the other three tests relative to control animals. Thus, despite clear evidence of graft survival and neurite extension, the functional benefit of hNT cells after ischemia is not guaranteed. Functional benefit could depend on other variables, such as infarct location, whether the cells mature, the behavioral tests employed, rehabilitation training, or as yet unidentified factors.

(c) 2006 Wiley-Liss, Inc.

Key words: ischemia; transplant; hNT cells; stem cells; behavior; cortical stroke

Cell transplantation offers therapeutic potential for a number of CNS disorders, including Parkinson's disease, Huntington's disease, and stroke (Bjorklund and Lindvall, 2000; Bjorklund et al., 2003; Isacson, 2003). Repair of the brain after stroke is a formidable task, be- cause the lesions are often large and involve cells of all types (including neural and endothelial cells), resulting in the loss of many complex synaptic connections. Despite this, bone marrow cells, trophic factor-secreting kidney cells, human neural stem cells, and immortalized cell lines have been transplanted into the ischemic striatum and, in many cases, have been shown to improve some index of behavioral function in animal stroke models (Borlongan et al., 1998c; Saporta et al., 1999; Nishino and Borlongan, 2000; Chen et al., 2001; Veizovic et al., 2001; Modo et al., 2002; Zhao et al., 2002; Savitz et al., 2003).

A cell type that has shown potential in an animal model of stroke and in clinical stroke trials is human hNT cells (also known as NT2N cells or LBS neurons). hNT cells are derived from embryonic carcinoma cells from a human teratocarcinoma (NT2 cells; Andrews et al., 1984). Treatment of NT2 cells with retinoic acid results in terminal differentiation into immature neurons (hNT cells), which maintain their neuronal phenotype both in vitro and in vivo for over 1 year without reverting to a neoplastic state (Pleasure and Lee, 1993; Trojanowski et al., 1993; Kleppner et al., 1995). These cells have been reported to improve functional recovery when transplanted into the ischemia-damaged striatum of rats (Borlongan et al., 1998b,c; Saporta et al., 1999).

The first two authors contributed equally to this work.

S. Kelly's current address is The Henry Wellcome Line, University of Bristol, Bristol BS8 1UQ, United Kingdom.

J. Masels's current address is Department of Ecology and Evolutionary Biology, University of Arizona, Tucson, AZ 85721.

^Correspondence to: Tonya Bliss, PhD, MSLS Bldg. p308, 1201 Welch Rd., Stanford, CA 94305. E-mail: tbliss1@stanford.edu

Received 29 November 2005; Accepted 1 January 2006

Published online 22 February 2006 in Wiley InterScience (www. interscience.wiley.com). DOI: 10.1002/jnr.20800 
hNT cells have also been used in clinical trials in patients with basal ganglia stroke, with promising preliminary results (Kondziolka et al., 2000, 2004; Meltzer et al., 2001; Nelson et al., 2002).

Most studies of cell transplantation for stroke, including those involving hNT cells, have assessed the effect of cell transplantation into the striatum after focal striatal ischemia (which can also damage the cortex to varying degrees). However, many stroke patients have damage restricted to the cortex with the striatum remaining intact. There are relatively few reports on transplantation into the ischemic cortex. Early studies of embryonic or fetal tissue transplanted into the lesioned cortex reported improved functional outcomes (Kesslak et al., 1986; Sinson et al., 1996). However, the effect of transplanting dissociated tissue or a renewable cell line (an ethically and practically more viable option) into the ischemic cortex is not well documented (Hadani et al., 1992). Furthermore, the requirements for repair of one brain region may differ from those for other brain regions. It remains to be seen whether transplanting cells into the cortex will show the same potential for inducing functional recovery as reported for striatal transplants (Nishino and Borlongan, 2000; Savitz et al., 2002).

This study describes for the first time the utility of transplanting hNT cells into the ischemic cortex. We used a model of stroke produced by permanent occlusion of the distal middle cerebral artery (dMCAo model), a reproducible stroke model in which damage is restricted to the frontal and parietal areas of the cortex and may extend into the underlying white matter (Brint et al., 1988; Markgraf et al., 1994; Roof et al., 2001). We examined the ability of transplanted hNT neurons to survive and integrate into the ischemic cortex and determined the effect of these cells on functional outcome by using a battery of sensorimotor behavior tests that are known to be sensitive to cortical injury caused by dMCAo.

\section{MATERIALS AND METHODS}

\section{dMCAo}

All experimental protocols performed on animals were approved by the Stanford University Administrative Panel on Laboratory Animal Care. Age-matched, adult, male SpragueDawley rats $(320 \pm 10 \mathrm{~g})$ were used. dMCAo was performed with rats under isoflurane anesthesia as previously described (Zhao et al., 2003). In brief, the distal portion of the MCA was exposed through a small burr hole made between the left eye and ear and cauterized and cut just above the rhinal fissure. Both common carotid arteries were occluded for $1 \mathrm{hr}$. Physiological parameters (EKG, core temperature, respiratory rate) were monitored and recorded throughout the procedure.

\section{Preparation of hNT Cells}

hNT cells (LBS neurons) were freshly prepared at Layton Biosciences using GMP (good manufacturing practice) and transplanted within $3 \mathrm{hr}$. In brief, cells were thawed and resuspended in isolyte $\mathrm{S}$ buffer, viability was tested, and cell

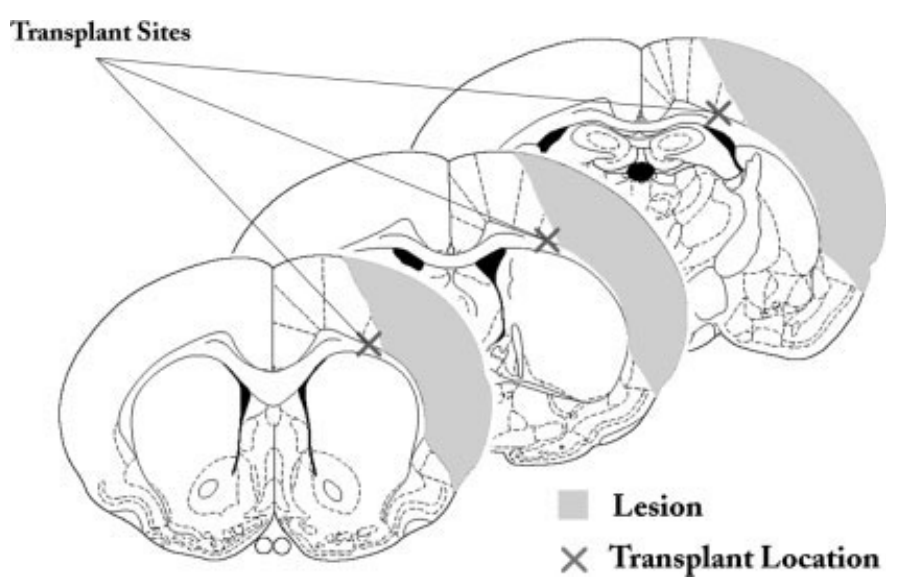

Fig. 1. Diagram of lesion position and transplant coordinates. hNT cells were transplanted into three cortical sites (marked with an $X$, 100,000 cells per site) along the A-P axis close to the lesion (gray area). The lesion is restricted to the cortex and underlying white matter; the striatum remains intact.

density was adjusted to give a final concentration of $1 \times 10^{5}$ cells $/ \mu 1$. Cell viability was $53-67 \%$ prior to transplant and exhibited at least $90 \%$ of this viability by the end of each transplantation session.

\section{Cortical Transplantation of hNT Cells}

Stereotaxic surgery was performed with animals under isoflurane anesthesia 7 days post-dMCAo. Rats were given three $1.0-\mu 1$ deposits of hNT cells $\left(1 \times 10^{5}\right.$ cells $/ \mu \mathrm{l}, \mathrm{n}=16$; or $1.0 \mu \mathrm{l}$ of buffer vehicle, $\mathrm{n}=11$ ) along the anterior-posterior axis into the cortex at the following coordinates: 1) A-P: +1; M-L: -2.5 ; D-V: -2.8 ; 2) A-P: -0.26 ; M-L: -2.9; D-V: -2.8 ; 3) A-P: -1.8 ; M-L: -2.4 ; D-V: -2.2 (Fig. 1). A microinfusion pump was used to control the speed of delivery at $0.5 \mu \mathrm{l} / \mathrm{min}$. The needle was left in situ for 2 min postinjection before being slowly removed. Cell-transplanted and control rats were immunosuppressed by daily intraperitoneal injection of cyclosporin A (CsA; $10 \mathrm{mg} / \mathrm{kg}$ ) from post-dMCAo days 6-35.

\section{Behavioral Testing}

We used a battery of previously described behavior tests. Forelimb usage for support and weight shifting during vertical exploration was assessed (Schallert et al., 2000). Rats were placed in a Plexiglas cylinder, and we counted the number of times the rat reared and touched the cylinder in a weightbearing fashion with the left, right, or both forelimbs. Approximately 20 of these limb-use movements were counted per trial.

Somatosensory asymmetry was also assessed. Small adhesive-backed stimuli (paper "dots") were placed on the distalradial part of each forelimb wrist, and the order of their removal (left vs. right) was recorded (Schallert et al., 1982, 1983, 2000; Schallert and Whishaw, 1984). The size of the dot on the preferred limb was reduced relative to the dot on the nonpreferred limb until preference disappeared. The mag- 


\section{Experimental Design}

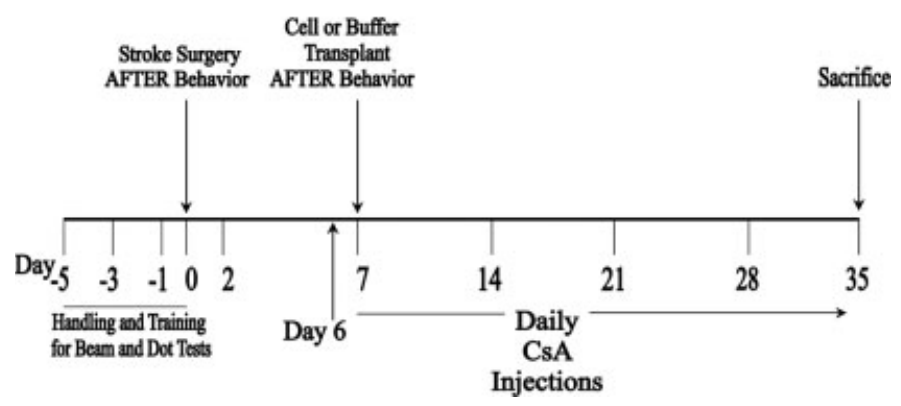

Fig. 2. Experimental design. Animals were trained 5 days prior to stroke. Behavior tests were carried out on day 0 (before stroke), on days 2 and 7 (after stroke, before transplantation), and then on days 14, 21, 28, and 35. All animals were given the immunosuppressant cyclosporin A (CsA) daily.

nitude of the sensory deficit is indicated by the ratio of the sizes of the contralateral and ipsilateral stimuli at which there was no preference. The maximal ratio (i.e., 7.5) was scored if rats always removed the dot from the unaffected limb regardless of the relative sizes of the dots.

Hind limb use was assessed using the ledged beam test (Schallert et al., 2002). Rats were trained to walk along a narrow beam that had a safety ledge on either side. A fault was recorded when a hind limb touched the ledge. The number of faults per step was recorded for each limb. Five beam runs were carried out per trial.

Turning bias after dMCAo was assessed by using the postural asymmetry test (Schallert et al., 1982, 1983; Borlongan et al., 1998c; Felt et al., 2002). Rats were held by the base of the tail approximately $4 \mathrm{~cm}$ above the bench. The direction toward which the rat turned its head $\left(>10^{\circ}\right)$ was recorded over 20 trials.

All rats were handled for 5 days and familiarized with the adhesive dot removal and ledged beam walking tests for 3 days prior to testing. All tests were carried out before dMCAo surgery on day 0 and on post-dMCAo days 2,7 (before transplant), 14, 21, 28, and 35 (Fig. 2).

\section{Tissue Processing}

Five weeks after dMCAo (4 weeks after transplantation) rats were transcardially perfused with heparinized saline $(0.5 \%)$ and fixed with ice-cold paraformaldehyde (PFA; 3\%). Brains were left in the skull overnight in 3\% PFA at $4^{\circ} \mathrm{C}$ before being transferred to $20 \%$ sucrose in PFA (3\%). Five equidistant sets of coronal sections $(40 \mu \mathrm{m}$ thick) were prepared on a cryostat and stored in cryoprotectant at $-20^{\circ} \mathrm{C}$ until required.

\section{Assessment of Cortical Lesion Size}

Very little ischemic tissue remained 5 weeks after dMCAo; in most rats, there was just an area of cortical tissue loss. Therefore, we estimated lesion size (as a percentage of the whole brain) by using the following formula: [(area of contralateral hemisphere - area of remaining ipsilateral hemi- sphere) $/$ (area of contralateral hemisphere) $] \times 100 / 2$. The areas of both the ipsilateral and the contralateral hemispheres were measured on eight serial coronal sections per brain, $200 \mu \mathrm{m}$ apart, stained with hematoxylin and eosin (H\&E). The area of the infarct was averaged over these eight levels.

\section{Immunohistochemical Staining}

Standard immunohistochemical staining techniques were used on free-floating sections. Sections were blocked in phosphate-buffered saline (PBS) containing 5\% normal serum of the species in which the secondary antibody was raised and $1 \%$ bovine seum albumin (BSA). All primary antibodies were diluted in PBS containing 1\% BSA and the same serum used in the block $(5 \%)$. Transplanted hNT cells were detected by labeling with antibodies specific to human nuclei (Chemicon, Temecula, CA), human-specific neurofilament light chain (NF-70; Chemicon), human-specific neuron-specific enolase (NSE; Novocastra Laboratories, Newcastle, United Kingdom), or MOC-1 (Dako, Carpinteria, CA); MOC-1 antibody recognizes human neural cell adhesion molecule (N-CAM). In brief, endogenous peroxidase activity was quenched with $\mathrm{H}_{2} \mathrm{O}_{2}(0.3 \%)$, and sections were then blocked for $30 \mathrm{~min}$ and incubated overnight at $4^{\circ} \mathrm{C}$ with anti-human nuclei antibody (1:30) or MOC-1 (1:100). Sections were washed and incubated with biotinylated secondary antibody (Vector Laboratories, Burlingame, CA) for 30 min, followed, after rinses, by a 30 min incubation with an avidin-biotin-peroxidase complex (ABC, Vectastain Elite; Vector Laboratories) and visualized with the chromogen Vector NovaRED or diaminobenzidine (DAB; Vector Laboratories). The following phenotypic antibodies were also used: guinea pig anti-GFAP (1:800; Advanced Immunochemical Inc., Long Beach, CA), rabbit anti-S100 (1:1,000; Sigma, St. Louis, MO), and guinea pig anti-VGlut1 (1:5,000; Chemicon) to detect vesicular glutamate transporters; rabbit anti-GAD65/67 (1:600; Chemicon) to mark GABAergic neurons; and goat anti-ChAT (1:500; Chemicon) to detect acetylcholine neurons. For fluorescent staining, the blocking and primary antibody steps were as described above. The secondary antibodies used $(1: 1,000,1 \mathrm{hr}$, room temperature) were Alexafluor 488 anti-guinea pig and Alexafluor 546 anti-mouse (Molecular Probes, Eugene, OR). Fluorescence-labeled sections were viewed with a confocal microscope. $Z$ stacks were obtained (optical section thickness of $1-\mu \mathrm{m}$; stack thickness between 14 and $33 \mu \mathrm{m}$ ), and projection images of these zstacks are shown.

\section{Unbiased Stereology and Cell Counting}

The MOC-1 staining gave an indication of the number of sections (per brain) that contained a bolus of cells as well as the relative size of the bolus in each animal. From this information, seven animals were chosen to determine hNT cell survival accurately, including the animal with the fewest cells, the one with the most cells, and representative animals in between. The number of surviving transplanted hNT cells was estimated by using unbiased computational stereology (fractionator method, in Stereoinvestigator software; MicroBrightField, Brattleboro, VT). The number of surviving transplanted hNT cells was estimated from sections stained with 

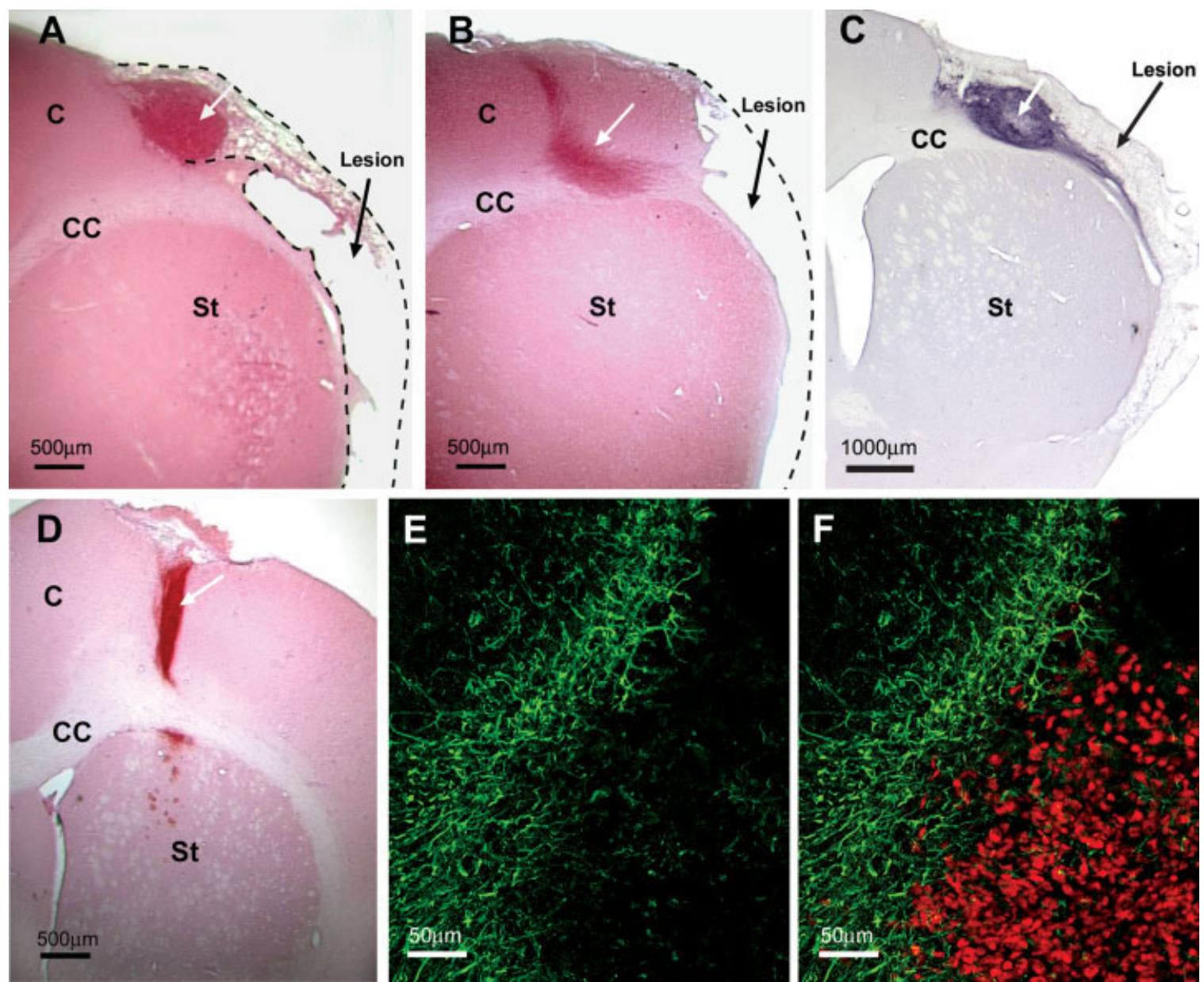

Fig. 3. hNT cell survival and neuronal phenotype. Four weeks posttransplant, hNT cells were stained with an anti-human-specific NCAM (A,B,D) or for the human-specific light chain (NF70; C). A-C show robust cell survival in the ischemic brain; $\mathbf{D}$ shows a graft in an uninjured brain. Note: the cells seen in the striatum in D have not migrated there but are from another graft site on the A-P

anti-human nuclei antibody and counted on every fifth section $(200 \mu \mathrm{m}$ apart) through the three transplantation sites. Transplanted hNT cell counts were corrected by using the Abercrombie correction factor (nuclear diameter $5.17 \mu \mathrm{m}$, determined from measurements of $>20$ hNT cell nuclei in our stained sample).

\section{Statistical Analysis}

Statistical analyses were performed by using a repeatedmeasures ANOVA. For the adhesive dot removal asymmetry test, the ANOVA was performed by using a generalized estimating equation with multinomal errors in SAS PROC GENMOD. For all other tests, the ANOVA was performed by using the generalized linear mixed model with autocorrelation of the binomial errors over time, using the SAS glimmix macro. Level of significance was defined a priori as $P<0.05$. Graphs were generated from mean and standard error measurements. axis that hit the striatum. Most hNT cells do not stain for GFAP $(\mathbf{E}, \mathbf{F})$; cells labeled with GFAP are green $(\mathrm{E}, \mathrm{F})$, cells stained with the human nuclear marker are red $(\mathrm{F})$. White arrow indicates the graft; black arrow indicates the lesion. c, cortex; cc, corpus callosum; St, striatum.

\section{RESULTS}

\section{Transplanted hNT Cells Survive Robustly in Ischemic Cortex}

Prominent grafts staining positively with an antibody against human-specific N-CAM (Fig. 3A,B) were seen in all animals at 4 weeks posttransplant, indicating robust survival of the transplanted hNT cells in the ischemic cortex even at the lesion border. The cells also stained positively for the neurofilament light chain NF-70 (Fig. 3C), and for neuron-specific enolase (see Fig. 6C), confirming their neuronal phenotype. Consistently with this, the grafts did not stain with the astrocytic marker glial fibrillary acidic protein (GFAP), although GFAP-positive host cells were seen around the edge of the graft (Fig. 3E,F). The few GFAP-positive cells within the graft are from the host, insofar as they do not colocalize with human nuclei (supplemental Fig. 1). A similar staining pattern was seen with 

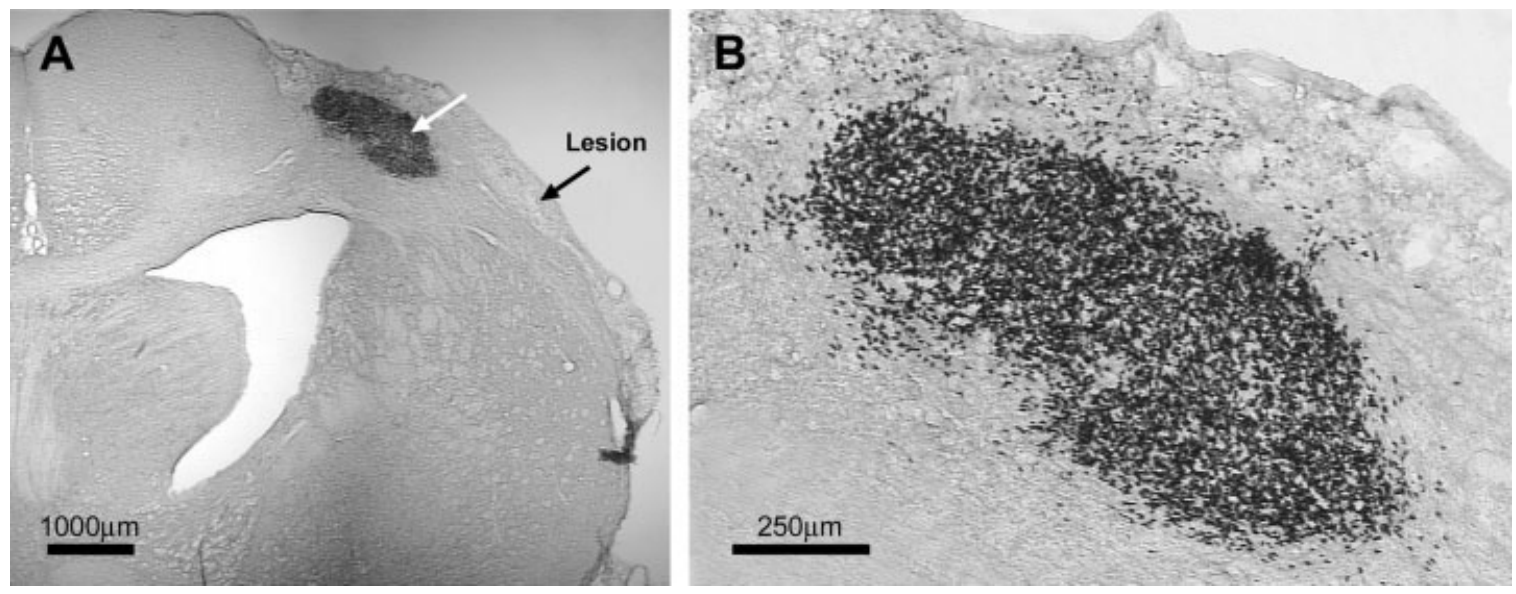

Fig. 4. hNT cell survival in the ischemic brain. Four weeks posttransplant, hNT cells were stained with a human nuclear marker (B shows a higher magnification of graft in $\mathbf{A}$ ). White arrow indicates the graft; black arrow indicates the lesion.

TABLE I. Comparison of Graft Survival With Lesion Size and Distance From the Lesion

\begin{tabular}{cccc}
\hline $\begin{array}{l}\text { Animal } \\
\text { No. }\end{array}$ & $\begin{array}{c}\text { Grafted cells } \\
\text { (\% survival) }\end{array}$ & $\begin{array}{c}\text { Lesion } \\
\text { size }(\%)\end{array}$ & $\begin{array}{c}\text { Graft: lesion } \\
\text { distance }(\mu \mathrm{m})\end{array}$ \\
\hline 1 & 49 & 8.7 & 0 \\
2 & 44 & 13.2 & 12 \\
3 & 41 & 11.1 & 0 \\
4 & 39 & 5.7 & 38 \\
5 & 38 & 11.9 & 118 \\
6 & 35 & 14.2 & 0 \\
7 & 31 & 20.2 & 0 \\
\hline
\end{tabular}

the astrocytic marker S100 $\beta$ (data not shown). Despite their neuronal phenotype, the grafts failed to stain with antibodies specific for glutamatergic, cholinergic, and GABAergic neurons (data not shown). Staining did occur in endogenous rat cells, so failure to find colabeling of the hNT cells was not due to failure of the immunohistochemical reaction.

To quantitate hNT cell survival, brains were stained with anti-human nuclei antibody so that individual cells could be identified (Fig. 4A,B), and cells were counted by using stereological methods. The proportion of transplanted hNT cells surviving in the ischemic cortex ranged from $31 \%$ to $49 \%$ (mean survival $39.6 \% \pm$ $2.2 \%)$, indicating that cell survival was very robust. There was a trend for animals with larger lesions to have less cell survival, but this was not statistically significant. There was no correlation of cell survival with distance of graft from the lesion (Table I). Despite extensive survival, there was no significant difference in lesion size between cell- and buffer-treated animals $(11 \% \pm 1 \%$ vs. $9 \% \pm 1 \%$, respectively). Survival of hNT cells in naïve brains was equally robust, although the graft was more elongated than the round bolus-type graft we typically found in the ischemic cortex (compare Fig. 3A,B with D).

\section{Transplanted hNT Cells Extend Processes Preferentially Toward the Cortical Lesion}

Transplanted hNT cells did not migrate; they survived where they were injected as fairly large cell boli (see Fig. 3). Cells in some of the transplants extended processes primarily along the white matter tracts of the corpus callosum; this was observed in $46 \%$ (6 of 13) of ischemic rats and $25 \%$ (1 of 4 ) of naïve rats. The lack of process extension from some grafts was mainly because there was no white matter left along the lesion edge for the processes to extend through or because the graft did not penetrate the white matter. Processes extended for up to $4.2 \mathrm{~mm}$, and the mean length was $2.1 \mathrm{~mm}$. In ischemic rats, processes extended predominantly through the white matter in the direction of the cortical lesion (Fig. 5A,B). Extension toward the midline was also seen, but these processes were usually much shorter than the lateral processes (Fig. 5A,B). Furthermore, in the two brains in which some cortex remained between the graft and the lesion, there was much greater process extension from the lateral side of the graft, the side of the graft nearer the lesion, than from the medial side of the graft (Fig. 6A-E). Overall, this suggests a preference for processes to extend toward the area of damage. No colocalization of these neurites and the synaptic marker synaptophysin was found (data not shown). In the one naive (no stroke) rat in which process extension was observed, processes extended bidirectionally, with similar distances in both directions (Fig. 6F).

\section{Effect of Transplanted hNT Cells on Behavioral Function}

Each behavioral test showed that the cortical stroke model, which damaged the frontal and parietal areas of the cortex, including the motor and somatosensory overlap regions of the cortex, produced measurable functional deficits with a bias toward greater use of the unaf- 

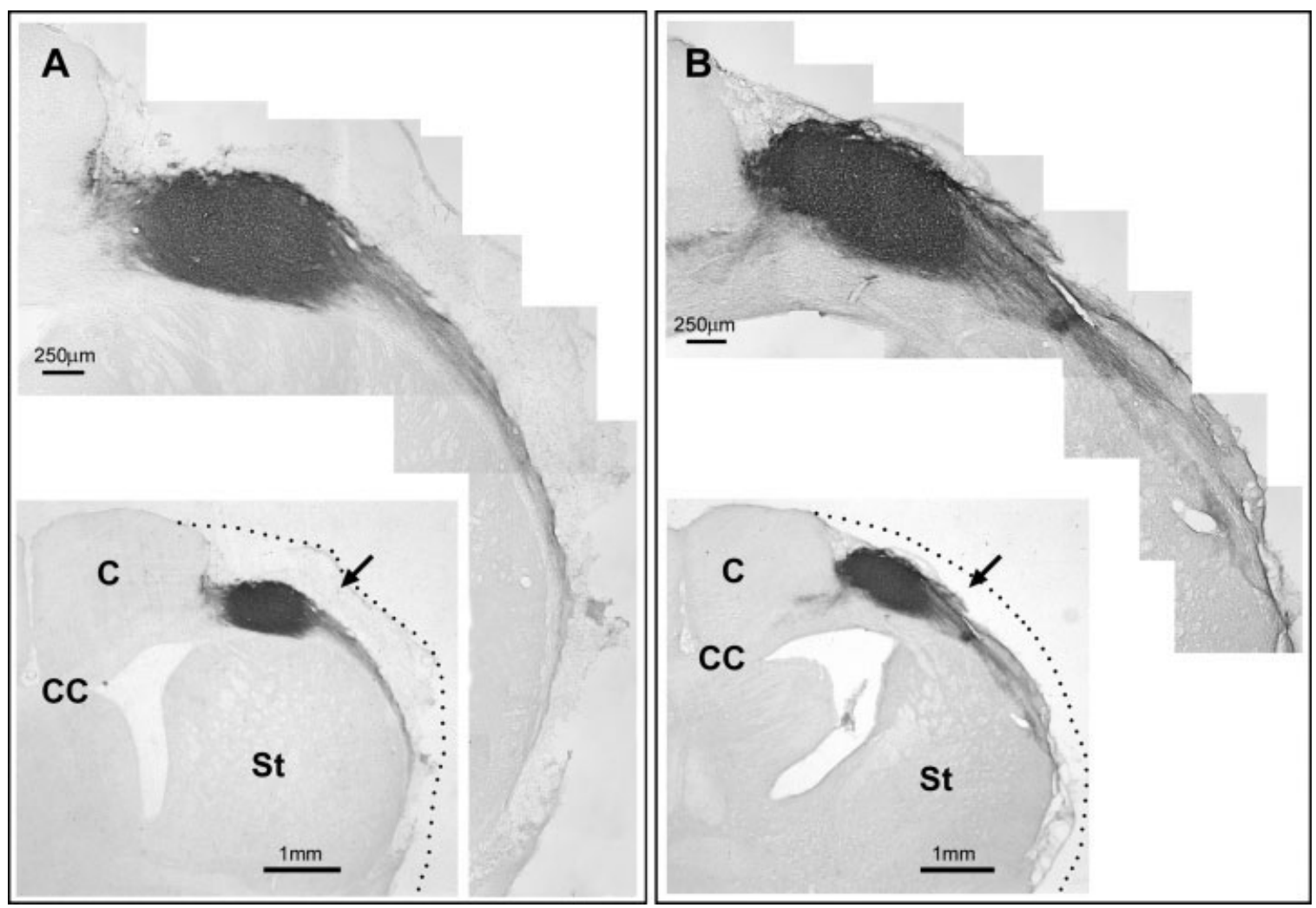

Fig. 5. hNT cells extend long processes through the white matter. hNT cells were stained with an anti-human-specific N-CAM. A,B: Representative images from two different ischemic brains showing hNT neurite extension through the white matter predominantly in the direction of the lesion. Insets show lower magnification of each image. Arrow indicates the lesion. c, cortex; cc, corpus callosum; St, striatum.

fected limb and less use of the affected limb (Fig. 7). There was no correlation between lesion size and the magnitude of the behavioral deficit in any of the tests. These deficits persisted for 5 weeks post-dMCAo, with very little spontaneous recovery, except in the ledged beam test, which showed recovery almost back to baseline in both groups (Fig. 7C). There was greater recovery in the ledged beam test in the cell-treated group compared with the buffer group. This was significant when taking into account total (i.e., $\mathrm{L}+\mathrm{R}$ ) foot faults $(P=0.0037)$ and approached significance $(P=0.082)$ when just considering faults of the affected (i.e., R) limb. There was no correlation between recovery in this test and lesion size, extent of cell survival, proximity of the graft to the lesion, or neurite extension of the transplanted cells. Despite surviving in high numbers and extending long processes, transplanted hNT cells had no significant effect, either positive or deleterious, on functional behavior in the other tests performed. Although there was no overall group effect on behavioral recovery, some individual rats showed recovery both in the buffer and in the cell groups. There was no correlation of recovery in these rats with any of the parameters mentioned above.

\section{DISCUSSION}

In contrast to the majority of studies in which various cell types, including hNT cells, were transplanted into the ischemia-damaged striatum, the present study investigated the effect of transplanting hNT cells into the ischemic cortex.

\section{hNT Cell Survival}

Extremely robust survival of the hNT cells was seen in the cortex of both naïve and stroke animals; in ischemic rats $31-49 \%$ (mean survival 39.6\% $\pm 2.2 \%$ ) of the initial transplanted cells survived. The majority of these grafts were found at the edges of lesions, suggesting that hNT cells can survive in ischemic tissue. This is in stark contrast to other cell types, which do not survive in such large numbers when transplanted too close to the ischemic lesion (Sinson et al., 1996; Kelly et al., 2004). This level of hNT survival is much greater than that reported previously with these cells, which is approximately 5-15\% (Borlongan et al., 1998a; Saporta et al., 1999, 2000). The difference may be due to the fact that cells were transplanted into different brain regions (i.e., cortex vs. striatum), and thus might have 

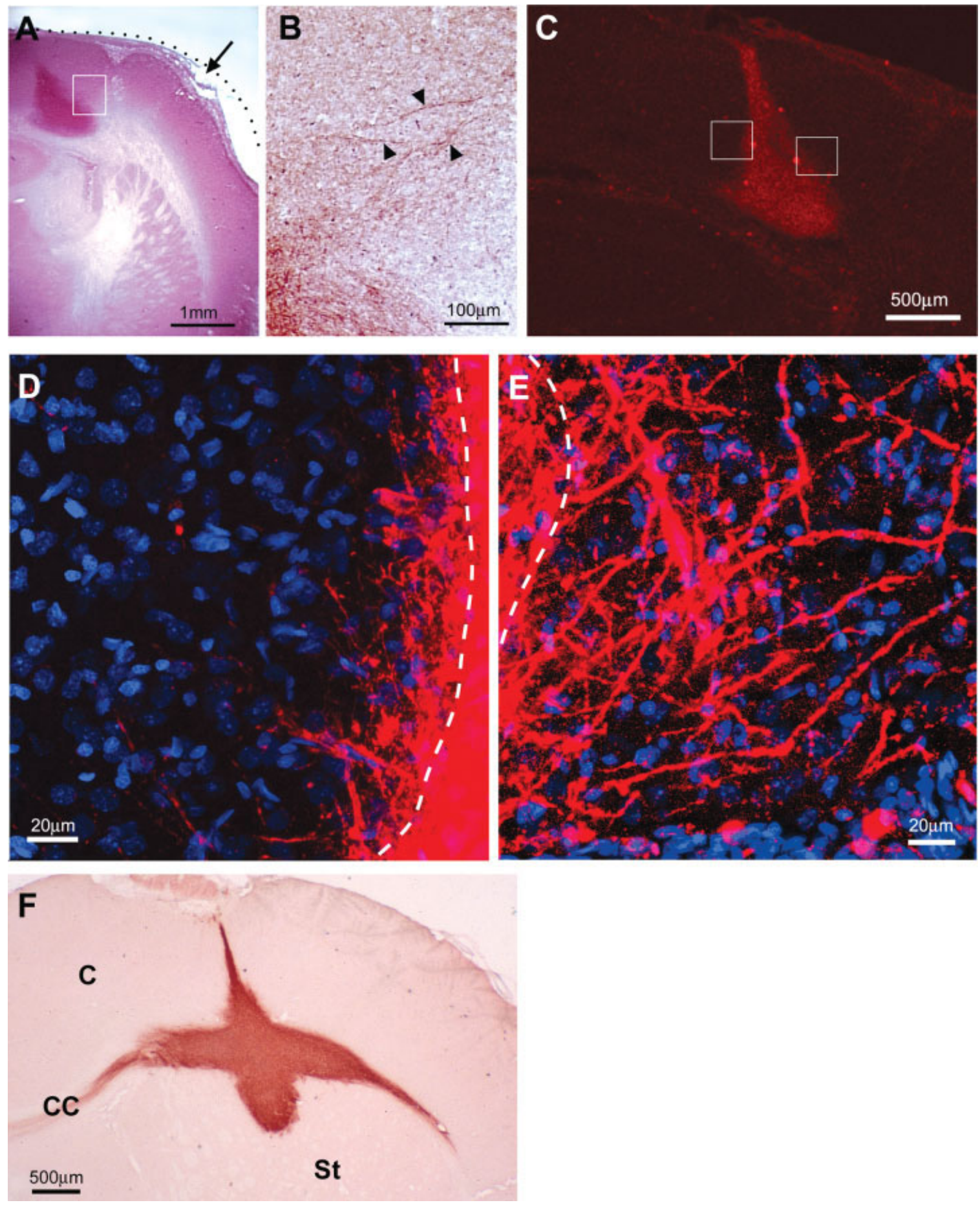

Fig. 6. hNT cells can extend processes through the cortex. hNT cells were stained with an anti-human-specific N-CAM $(\mathbf{A}, \mathbf{B}, \mathbf{F})$ or with human-specific neuron-specific enolase (NSE; C-E). hNT cells can extend neurites (arrowheads in $\mathrm{B}$ ) through the cortex toward the lesion (A-E). Boxed area in A is shown at higher magnification in B. C: Low-magnification confocal image showing specific staining of the graft with NSE. This section is taken from the same brain as that used in A.
D: Higher magnification of the medial edge of the graft (left box in C). White dotted line indicates the edge of the graft. Red: NSE; blue: DAPI. E: Higher magnification of the lateral edge of the graft (the edge toward the lesion; right box in C). F: In uninjured animals, neurites can extend bidirectionally through the white matter. Arrow indicates the lesion. c, cortex; cc, corpus callosum; St, striatum. 
A

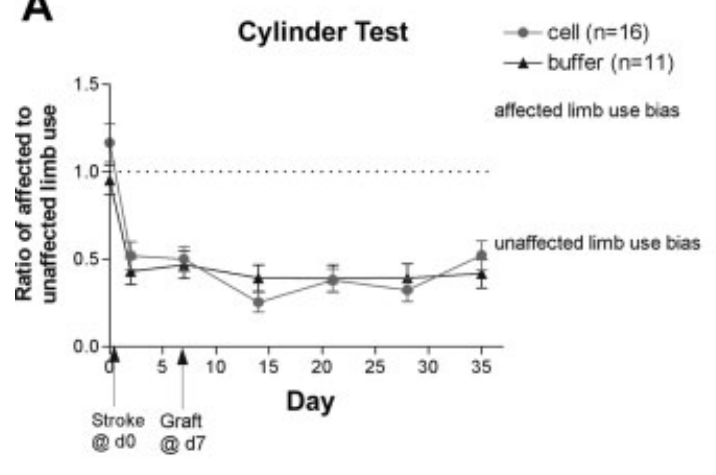

C

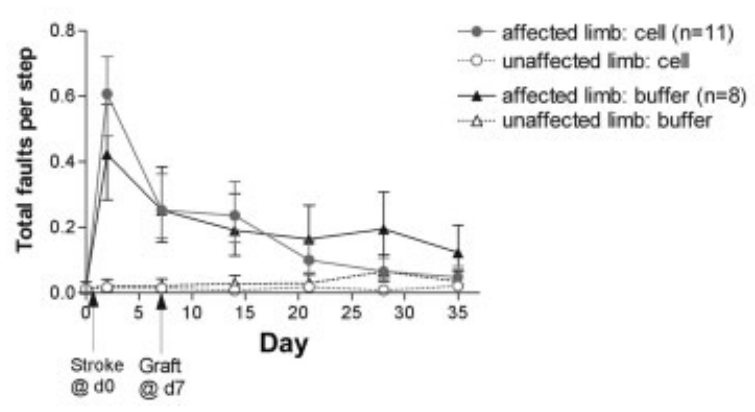

B
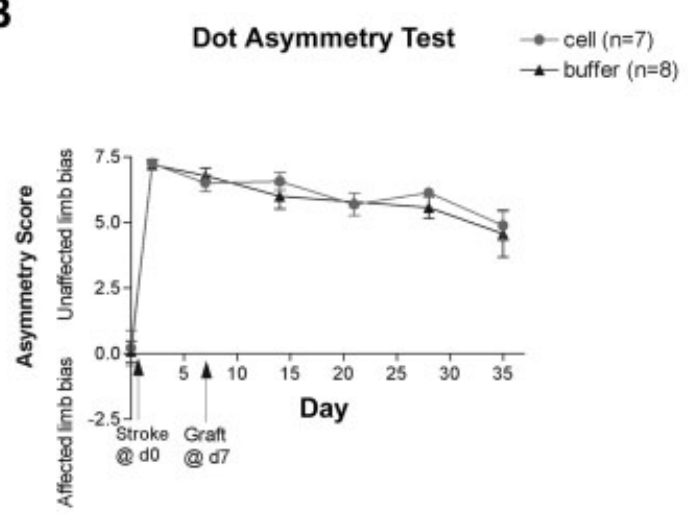

D

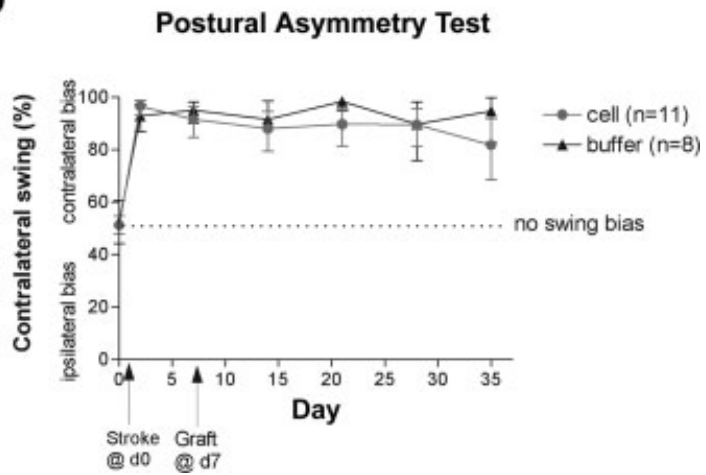

Fig. 7. A-D: Effect of hNT cells on behavior. All behavior tests showed a functional deficit after ischemia (compare day 0 vs. day 2). There was very little spontaneous recovery over time, except in the ledged beam test (C). There was a significant difference in behavior only between cell- and buffer-transplanted animals in the ledged beam test.

been exposed to environments that differentially influenced survival. However, Saporta et al. (2000) reported a similar extent of survival of cells transplanted into the cortex and the striatum. Differences in cell handling and preparation might also have contributed significantly to this dramatic difference in cell survival.

\section{hNT Cell Neurite Extension}

Consistent with previous studies with hNT cells, we saw no cell migration into the surrounding parenchyma. However, in many cases, the grafts extended neurites into the surrounding host tissue, mainly through the surrounding white matter, as reported in other studies (Trojanowski et al., 1993; Kleppner et al., 1995; Muir et al., 1999; Philips et al., 1999; Lee et al., 2000), although a clear boundary remained between the graft and the host. There were a few grafts in both naïve and ischemic animals that showed little process extension; in ischemic animals, these were usually in animals with little remaining white matter. When process extension was observed in naïve animals, it was bidirectional (i.e., medial and lateral), whereas, in ischemic animals, long process extension was primarily in the direction of the lesion. In contrast, a previous study in which hNT cells were transplanted into the ischemic striatum showed little neurite outgrowth (Saporta et al., 1999). We also observed processes extending through the ischemic cortex toward the lesion in two animals in which some intact cortex remained between the graft and the lesion. It is tempting to speculate that the cells respond to environmental cues from the lesion and target processes toward the damage. An alternative explanation is that the tissue is less compact near the lesion and that cell processes simply followed a path of least resistance.

\section{hNT Cell Differentation}

Several studies have shown that hNT cells maintain a neuronal phenotype in vivo and also express phenotypic markers appropriate for the host brain region. These findings suggest that the cells respond to local environmental cues (Saporta et al., 2000). In our study, hNT cells reacted with antibodies against a neural cell adhesion molecule, a neurofilament marker, neuron-specific enolase, but not with astrocytic markers; this is consistent with the cells being neurons (Kleppner et al., 1995). The cortex contains glutamatergic, cholinergic, and $\gamma$ aminobutyric acid (GABA)-ergic neurons, but we found that none of the transplanted hNT cells colabeled with 
markers for them (data not shown), suggesting perhaps that the cells were not yet functionally mature at 4 weeks posttransplantation. In keeping with this hypothesis, the hNT cell neurites did not colocalize with synaptophysin staining, which suggests that they were not yet forming synapses. Other groups have also failed to find hNT cells expressing mature phenotypic markers (Saporta et al., 2000; Fricker-Gates et al., 2004). This is consistent with the notion that human cells take longer to mature in the rodent brain than rodent stem cells. Thus, longer time points may be required to detect mature neurons, or perhaps the brain environment after injury is just not conducive to hNT cell maturation. The lack of cell maturation may account for the inability of hNT cells to enhance behavioral recovery in this study.

\section{Effect of hNT Cells on Behavior}

All four behavioral tests revealed significant deficits after cortical stroke and, except in the ledged beam test, these persisted throughout the 5-week period of study. In previous studies in which MCAo damaged the striatum (and hindlimb area of sensorimotor cortex), spontaneous recovery in the ledged beam test did not occur (Schallert et al., 2002). Roof et al. (2001) reported a prolonged deficit in the cylinder test in their cortical stroke model, but they found greater spontaneous recovery in the hangtail test. In our study, performance on the ledged beam test appeared to recover spontaneously almost back to baseline. Animals receiving cell transplants showed a significant improvement in the ledged beam test compared with the buffer group. However, there was no significant difference in behavior between cell- and buffer-treated animals in the other behavior tests. This suggests that improvement in motor function was not a general phenomenon and may be dependent on the behavioral test (Markgraf et al., 1994). Other groups reported similar results; despite good cell survival, they saw no improvement in functional behavior either following transplantation of hNT cells into the cortex after traumatic brain injury (Muir et al., 1999; Philips et al., 1999) or after transplantation into the striatum in a rat model of Huntington's disease (FrickerGates et al., 2004). Consistent with other reports, there was no evidence that the cells had any deleterious effects on behavior (Muir et al., 1999; Philips et al., 1999) despite the grafts disrupting the laminar structure of the cortex.

These data differ from the studies of Borlongan et al. (1998b,c; Saporta et al., 1999) showing greater recovery of motor function after stroke within 1 month of receiving transplants of hNT cells into the striatum. Several differences between the studies may account for this disparity. First, Borlongan et al. transplanted 1 month postischemia and we transplanted 1 week postischemia. It is well documented that the inflammatory response (with respect to the magnitude of the response and the cytokines present) following ischemia changes with time (Barone and Feuerstein, 1999; Danton and Dietrich,
2003). Therefore, regardless of where cells are transplanted, the environment they are exposed to will differ at 1 week vs. 4 weeks poststroke. Cytokines present at 1 week may interfere with the regenerative potential of both the graft and the host cells. hNT cells have been shown to express cytokine receptors (Hesselgesser et al., 1997), so it is possible that hNT cells are influenced by the inflammatory response, perhaps affecting their maturation. Second, the stroke model used by Borlongan et al. primarily damages the striatum, with some cortical damage (Nishino et al., 1993). In our model, the striatum remains intact, and it is likely that a greater extent of the motor cortex is damaged compared with Borlongan's model, both factors that will influence motor function recovery (Markgraf et al., 1994). Third, they transplanted cells into the striatum, whereas we transplanted into the cortex. Perhaps hNT cells behave differently in the striatum compared with the cortex such that they can facilitate recovery, or perhaps the damaged striatum is more conducive to repair by transplanted cells than the cortex. The literature on cortical transplants and functional recovery is divided (Gates et al., 2000; Dobrossy and Dunnett, 2001); some groups report that grafts of primary fetal tissue improved motor performance after cortical infarcts (Kesslak et al., 1986; Sinson et al., 1996); others report no amelioration of motor dysfunction with such grafts (Dunnett et al., 1987; Sofroniew et al., 1990; Kolb and Fantie, 1994). There is also evidence that functional recovery after cortical transplants may be dependent on the animals "learning to use" the transplant (Dunnett et al., 1986; Mayer et al., 1992; Dobrossy and Dunnett, 2001; Riolobos et al., 2001; Kleim et al., 2003). Behavioral training may increase the likelihood that the graft makes useful connections or permit host tissue to allow more effective connections (Jones and Schallert, 1994). Such training may be necessary for the transplanted cells to have a therapeutic effect in the cortex.

It is also possible that the outcomes of the behavioral tests used to detect impairment and recovery are susceptible to different interpretations. Borlongan and colleagues used passive avoidance and postural asymmetry tests. Passive avoidance is influenced by motor impairments associated with basal ganglia dysfunction and might have been exaggerated by grafts in the striatal infarct model. If this is so, the animals might be more likely to avoid the location in which they were previously shocked, not because of improved memory but because they were less prone to move. In the postural asymmetry test (elevated body swing test), the direction of postural asymmetry differs in cortical vs. striatal models and between striatal models in which the intrinsic striatal cells vs. nigrostriatal afferents are damaged. In the cortical models, the direction of turning is contralateral, because of a failure to show proprioceptive placing by the affected limb (Whishaw et al., 1981; Kolb and Whishaw, 1985). In contrast, the direction of turning is ipsilateral following nigrostriatal afferent damage (due to a postural asymmetry that overwhelms the placing asym- 
metry in this test) and can be contralateral or ipsilateral in models of damage to the intrinsic neurons (Schallert et al., 1982, 1983, 2000; Felt et al., 2002). Thus, a graft conceivably could counteract an infarct-induced asymmetry by impairing function rather than improving function. Of course, these are merely speculations, but they suggest that it would be worth exploring the striatal infarct model more thoroughly by using other behavioral tests. It would be necessary to compare cortical and striatal transplants using the same cells, behavior tests, and timing of transplantation before truly conclusive statements can be made about location-specific effects of the transplanted cells.

\section{CONCLUSIONS}

In conclusion, this study has shown that hNT cells transplanted into the ischemic cortex show extremely robust survival and extend long neurites through the white matter and the cortex, primarily, but not exclusively, toward the lesion. Despite this, recovery of function was observed in only one of four behavioral tests. Whether this lack of functional recovery is reflective of the location (i.e., the cortex) or the timing of the transplant or of the ability of the cells to mature is not clear. It might simply be that the cortical lesion is too large and that too many connections are severed to make repair feasible. It is evident that graft survival alone is not sufficient to enhance functional recovery. Thus, if cell transplantation is to be used to repair cortical damage, several complex issues concerning the location and severity of the damage and the timing and location of the transplant will have to be addressed.

\section{ACKNOWLEDGMENTS}

We thank Ray Sobel for help with microscopy, Beth Hoyte for help with the figures, Hayden Rausch for help with the stereology, Brandi Ormerod for help with confocal microscopy, Unsal Kuscuoglu for help with immunohistochemistry, and Dave Schaal for critical reading of the manuscript. This work was supported in part by National Institutes of Health, National Institute of Neurological Disorders and Stroke, grant P01 NS37520 (to G.K.S.).

\section{REFERENCES}

Andrews PW, Damjanov I, Simon D, Banting GS, Carlin C, Dracopoli NC, Fogh J. 1984. Pluripotent embryonal carcinoma clones derived from the human teratocarcinoma cell line Tera-2. Differentiation in vivo and in vitro. Lab Invest 50:147-162.

Barone FC, Feuerstein GZ. 1999. Inflammatory mediators and stroke: new opportunites for novel therapeutics. J Cereb Blood Flow Metab 19:819-834.

Bjorklund A, Lindvall O. 2000. Cell replacement therapies for central nervous system disorders. Nat Neurosci 3:537-544.

Bjorklund A, Dunnett SB, Brundin P, Stoessl AJ, Freed CR, Breeze RE, Levivier M, Peschanski M, Studer L, Barker R. 2003. Neural transplantation for the treatment of Parkinson's disease. Lancet Neurol 2:437-445.

Borlongan CV, Saporta S, Poulos SG, Othberg A, Sanberg PR. 1998a. Viability and survival of hNT neurons determine degree of functional recovery in grafted ischemic rats. Neuroreport 9:2837-2842.
Borlongan CV, Tajima Y, Trojanowski JQ, Lee VM, Sanberg PR. 1998b. Cerebral ischemia and CNS transplantation: differential effects of grafted fetal rat striatal cells and human neurons derived from a clonal cell line. Neuroreport 9:3703-3709.

Borlongan CV, Tajima Y, Trojanowski JQ, Lee VM, Sanberg PR. 1998c. Transplantation of cryopreserved human embryonal carcinomaderived neurons (NT2N cells) promotes functional recovery in ischemic rats. Exp Neurol 149:310-321.

Brint S, Jacewicz M, Kiessling M, Tanabe J, Pulsinelli W. 1988. Focal brain ischemia in the rat: methods for reproducible neocortical infarction using tandem occlusion of the distal middle cerebral and ipsilateral common carotid arteries. J Cereb Blood Flow Metab 8:474-485.

Chen J, Li Y, Wang L, Lu M, Zhang X, Chopp M. 2001. Therapeutic benefit of intracerebral transplantation of bone marrow stromal cells after cerebral ischemia in rats. J Neurol Sci 189:49-57.

Danton GH, Dietrich WD. 2003. Inflammatory mechanisms after ischemia and stroke. J Neuropathol Exp Neurol 62:127-136.

Dobrossy MD, Dunnett SB. 2001. The influence of environment and experience on neural grafts. Nat Rev Neurosci 2:871-879.

Dunnett SB, Whishaw IQ, Bunch ST, Fine A. 1986. Acetylcholine-rich neuronal grafts in the forebrain of rats: effects of environmental enrichment, neonatal noradrenaline depletion, host transplantation site and regional source of embryonic donor cells on graft size and acetylcholinesterase-positive fibre outgrowth. Brain Res 378:357-373.

Dunnett SB, Ryan CN, Levin PD, Reynolds M, Bunch ST. 1987. Functional consequences of embryonic neocortex transplanted to rats with prefrontal cortex lesions. Behav Neurosci 101:489-503.

Felt BT, Schallert T, Shao J, Liu Y, Li X, Barks JD. 2002. Early appearance of functional deficits after neonatal excitotoxic and hypoxic-ischemic injury: fragile recovery after development and role of the NMDA receptor. Dev Neurosci 24:418-425.

Fricker-Gates RA, Muir JA, Dunnett SB. 2004. Transplanted hNT cells ("LBS neurons") in a rat model of Huntington's disease: good survival, incomplete differentiation, and limited functional recovery. Cell Transplant 13:123-136.

Gates MA, Fricker-Gates RA, Macklis JD. 2000. Reconstruction of cortical circuitry. Prog Brain Res 127:115-156.

Hadani M, Freeman T, Munsiff A, Young W, Flamm E. 1992. Fetal cortical cells survive in focal cerebral infarct after permanent occlusion of the middle cerebral artery in adult rats. J Neurotrauma 9:107-112.

Hesselgesser J, Halks-Miller M, DelVecchio V, Peiper SC, Hoxie J, Kolson DL, Taub D, Horuk R. 1997. CD4-independent association between HIV-1 gp120 and CXCR4: functional chemokine receptors are expressed in human neurons. Curr Biol 7:112-121.

Isacson O. 2003. The production and use of cells as therapeutic agents in neurodegenerative diseases. Lancet Neurol 2:417-424.

Jones TA, Schallert T. 1994. Use-dependent growth of pyramidal neurons after neocortical damage. J Neurosci 14:2140-2152.

Kelly S, Bliss TM, Shah AK, Sun GH, Ma M, Foo WC, Masel J, Yenari MA, Weissman IL, Uchida N, Palmer T, Steinberg GK. 2004. Transplanted human fetal neural stem cells survive, migrate, and differentiate in ischemic rat cerebral cortex. Proc Natl Acad Sci U S A 101:11839-11844.

Kesslak JP, Brown L, Steichen C, Cotman CW. 1986. Adult and embryonic frontal cortex transplants after frontal cortex ablation enhance recovery on a reinforced alternation task. Exp Neurol 94:615-626.

Kleim JA, Jones TA, Schallert T. 2003. Motor enrichment and the induction of plasticity before or after brain injury. Neurochem Res 28:1757-1769.

Kleppner SR, Robinson KA, Trojanowski JQ, Lee VM. 1995. Transplanted human neurons derived from a teratocarcinoma cell line (NTera-2) mature, integrate, and survive for over 1 year in the nude mouse brain. J Comp Neurol 357:618-632.

Kolb B, Fantie B. 1994. Cortical graft function in adult and neonatal rats. In: Dunnett SB, Bjorklund A, editors. Functional neural transplantation. New York: Raven. p 415-436. 
Kolb B, Whishaw IQ. 1985. An observer's view of locomotor asymmetry in the rat. Neurobehav Toxicol Teratol 7:71-78.

Kondziolka D, Wechsler L, Goldstein S, Meltzer C, Thulborn KR, Gebel J, Jannetta P, DeCesare S, Elder EM, McGrogan M, Reitman MA. 2000. Transplantation of cultured human neuronal cells for patients with stroke. Neurology 55:565-569.

Kondziolka D, Steinberg GK, Wechsler L, Meltzer C, Elder E, Gebel J, DeCesare S, Jovin T, Zafonte R, Leibrowitz J, Flickinger JC, Tong D, Marks M, Jamieson C, Luu D, Bell-Stephens T, Teraoka J. 2004. Neurotransplantation for patients with subcortical motor stroke: a phase 2 randomized trial. J Neurosurg J Neurosurg (submitted).

Lee VM, Hartley RS, Trojanowski JQ. 2000. Neurobiology of human neurons (NT2N) grafted into mouse spinal cord: implications for improving therapy of spinal cord injury. Prog Brain Res 128:299307.

Markgraf CG, Green EJ, Watson B, McCabe PM, Schneiderman N, Dietrich WD, Ginsberg MD. 1994. Recovery of sensorimotor function after distal middle cerebral artery photothrombotic occlusion in rats. Stroke 25:153-159.

Mayer E, Brown VJ, Dunnett SB, Robbins TW. 1992. Striatal graft-associated recovery of a lesion-induced performance deficit in the rat requires learning to use the transplant. Eur J Neurosci 4:119-126.

Meltzer CC, Kondziolka D, Villemagne VL, Wechsler L, Goldstein S, Thulborn KR, Gebel J, Elder EM, DeCesare S, Jacobs A. 2001. Serial $\left[{ }^{18} \mathrm{~F}\right]$ fluorodeoxyglucose positron emission tomography after human neuronal implantation for stroke. Neurosurgery 49:586-591; discussion 591-582.

Modo M, Stroemer RP, Tang E, Patel S, Hodges H. 2002. Effects of implantation site of stem cell grafts on behavioral recovery from stroke damage. Stroke 33:2270-2278.

Muir JK, Raghupathi R, Saatman KE, Wilson CA, Lee VM, Trojanowski JQ, Philips MF, McIntosh TK. 1999. Terminally differentiated human neurons survive and integrate following transplantation into the traumatically injured rat brain. J Neurotrauma 16:403-414.

Nelson PT, Kondziolka D, Wechsler L, Goldstein S, Gebel J, DeCesare S, Elder EM, Zhang PJ, Jacobs A, McGrogan M, Lee VM, Trojanowski JQ. 2002. Clonal human (hNT) neuron grafts for stroke therapy: neuropathology in a patient 27 months after implantation. Am J Pathol 160: 1201-1206.

Nishino H, Borlongan CV. 2000. Restoration of function by neural transplantation in the ischemic brain. Prog Brain Res 127:461-476.

Nishino H, Koide K, Aihara N, Kumazaki M, Sakurai T, Nagai H. 1993. Striatal grafts in the ischemic striatum improve pallidal GABA release and passive avoidance. Brain Res Bull 32:517-520.

Philips MF, Muir JK, Saatman KE, Raghupathi R, Lee VM, Trojanowski JQ, McIntosh TK. 1999. Survival and integration of transplanted postmitotic human neurons following experimental brain injury in immunocompetent rats. J Neurosurg 90:116-124.

Pleasure SJ, Lee VM. 1993. NTera 2 cells: a human cell line which displays characteristics expected of a human committed neuronal progenitor cell. J Neurosci Res 35:585-602.

Riolobos AS, Heredia M, de la Fuente JA, Criado JM, Yajeya J, Campos J, Santacana M. 2001. Functional recovery of skilled forelimb use in rats obliged to use the impaired limb after grafting of the frontal cortex lesion with homotopic fetal cortex. Neurobiol Learn Mem 75:274-292.
Roof RL, Schielke GP, Ren X, Hall ED. 2001. A comparison of longterm functional outcome after 2 middle cerebral artery occlusion models in rats. Stroke 32:2648-2657.

Saporta S, Borlongan CV, Sanberg PR. 1999. Neural transplantation of human neuroteratocarcinoma (hNT) neurons into ischemic rats. A quantitative dose-response analysis of cell survival and behavioral recovery. Neuroscience 91:519-525.

Saporta S, Willing AE, Colina LO, Zigova T, Milliken M, Daadi MM, Sanberg PR. 2000. In vitro and in vivo characterization of hNT neuron neurotransmitter phenotypes. Brain Res Bull 53:263-268.

Savitz SI, Rosenbaum DM, Dinsmore JH, Weschler LR, Caplan LR. 2002. Cell transplantation for stroke. Ann Neurol 53:266-275.

Savitz SI, Malhotra S, Gupta G, Rosenbaum DM. 2003. Cell transplants offer promise for stroke recovery. J Cardiovascular Nursing 18:57-61.

Schallert T, Whishaw IQ. 1984. Bilateral cutaneous stimulation of the somatosensory system in hemidecorticate rats. Behav Neurosci 98:518540.

Schallert T, Upchurch M, Lobaugh N, Farrar SB, Spirduso WW, Gilliam P, Vaughn D, Wilcox RE. 1982. Tactile extinction: distinguishing between sensorimotor and motor asymmetries in rats with unilateral nigrostriatal damage. Pharmacol Biochem Behav 16:455-462.

Schallert T, Upchurch M, Wilcox RE, Vaughn DM. 1983. Postureindependent sensorimotor analysis of inter-hemispheric receptor asymmetries in neostriatum. Pharmacol Biochem Behav 18:753-759.

Schallert T, Fleming SM, Leasure JL, Tillerson JL, Bland ST. 2000. CNS plasticity and assessment of forelimb sensorimotor outcome in unilateral rat models of stroke, cortical ablation, parkinsonism and spinal cord injury. Neuropharmacology 39:777-787.

Schallert T, Woodlee MT, Fleming SM. 2002. Disentangling multiple types of recovery from brain injury. In: Klumpp JK, editor. Pharmacology of cerebral ischemia. Stuttgart: Medpharm Scientific Publishers. p 201-216.

Sinson G, Voddi M, McIntosh TK. 1996. Combined fetal neural transplantation and nerve growth factor infusion: effects on neurological outcome following fluid-percussion brain injury in the rat. J Neurosurg 84:655-662.

Sofroniew MV, Dunnett SB, Isacson O. 1990. Remodelling of intrinsic and afferent systems in neocortex with cortical transplants. Prog Brain Res 82:313-320.

Trojanowski JQ, Mantione JR, Lee JH, Seid DP, You T, Inge LJ, Lee VM. 1993. Neurons derived from a human teratocarcinoma cell line establish molecular and structural polarity following transplantation into the rodent brain. Exp Neurol 122:283-294.

Veizovic T, Beech JS, Stroemer RP, Watson WP, Hodges H. 2001. Resolution of stroke deficits following contralateral grafts of conditionally immortal neuroepithelial stem cells. Stroke 32:1012-1019.

Whishaw IQ, Schallert T, Kolb B. 1981. An analysis of feeding and sensorimotor abilities of rats after decortication. J Comp Physiol Psychol 95:85-103.

Zhao H, Yenari MA, Cheng D, Sapolsky RM, Steinberg GK. 2003. Bcl-2 overexpression protects against neuron loss within the ischemic margin following experimental stroke and inhibits cytochrome c translocation and caspase-3 activity. J Neurochem 85:1026-1036.

Zhao LR, Duan WM, Reyes M, Keene CD, Verfaillie CM, Low WC. 2002. Human bone marrow stem cells exhibit neural phenotypes and ameliorate neurological deficits after grafting into the ischemic brain of rats. Exp Neurol 174:11-20. 